\title{
РАЗРАБОТКА СКОРИНГОВОЙ МОДЕЛИ ОЦЕНКИ КРЕДИТНОГО РИСКА
}

\author{
Нозимов Элдор Анварович \\ ассистент \\ Самаркандский институт экономики и сервиса
}

\begin{abstract}
Аннотация. Исследовалась кредитоспособность заемщиков на основе клиентской базы банка. Было сформировано факторное пространство, позволяющее формализовать и объяснить различия между классами прежних заемщиков. Выявлены факторы, вносящие наибольший вклад в различение классов. В результате проведения дискриминантного анализа разработана скоринговая модель оценки кредитного риска, позволяющая адекватно и быстро оценить кредитоспособность потенциального клиента банка, что способствует росту конкурентоспособности на рынке кредитования.
\end{abstract}

Abstract. The creditworthiness of borrowers was investigated on the basis of the bank's client base. A factor space was formed to formalize and explain the differences between the classes of former borrowers. The factors that make the greatest contribution to the differentiation of classes are revealed. As a result of the discriminant analysis, a scoring model for assessing credit risk was developed, which makes it possible to adequately and quickly assess the creditworthiness of a potential client of the bank, which contributes to the growth of competitiveness in the lending market.

Ключевые слова: банк, кредит, риски, скоринговая модель, дискриминантный анализ, классификация.

Key words: bank, credit, risks, scoring model, discriminant analysis, classification.

В настоящее время в России наблюдается интенсивный рост рынка кредитования и, в частности, сектора кредитования физических лиц, что неизбежно приводит к увеличению кредитных рисков, которые

принимают на себя как отдельные кредитно-финансовые институты, так и банковская система страны в целом. Рост рисков обуславливается одновременно расширением контингента заемщиков и увеличением объемов кредитования. В этой ситуации качество управления кредитными рисками в розничном кредитовании приобретает особую актуальность и становится одним из факторов повышения конкурентоспособности кредитного учреждения на рынке банковских услуг [1].

При принятии решения о выдаче кредита тому или иному лицу банками используются различные методики и подходы к оценке кредитоспособности заемщика. К таковым относятся как субъективные

оценки банковских специалистов, так и автоматизированные системы оценки риска. С их помощью банки определяют возможность потенциального заемщика возвратить в необходимый срок основную сумму кредита и уплатить проценты по нему. Эффективное и качественное проведение оценки кредитоспособности потенциального клиента способствует минимизации кредитного риска.

Статистический метод скоринг-анализа является одним из инструментов оценки кредитного риска, который применяется сегодня во многих банках по всему миру. С его помощью проводится оценка кредитоспособности потенциальных заемщиков. Наиболее часто скоринг применяется банками при потребительском экспресскредитовании и оформлении кредитных карт.

Целью работы являлась разработка скоринговой модели на основе клиентской базы банка и анализ кредитоспособности заемщиков - физических лиц. При выполнении работы данные использовались с учетом конфиденциальности информации, принятой в банке. Скоринговая модель

разрабатывалась на основе проведения канонического дискриминантного анализа.

В работе исследовались два класса заемщиков банка, представленные своими типичными представителями, отобранными из клиентской базы. К первому классу относятся прошлые заемщики с положительными кредитными историями (класс 0), ко второму классу, соответственно, прошлые заемщики, кредитные истории которых содержат сведения о существенной просрочке платежей либо прекращении выплат по кредиту (класс 1). Для проведения анализа из клиентской базы были отобраны данные 350 клиентов, 300 из которых выполняли функции обучающей выборки, а оставшиеся 50 не входили в состав обучающей выборки, а задействовались для оценки качества модели.

На первом этапе исследования формировалось факторное пространство, позволяющее различить рассматриваемые классы заемщиков. В качестве дискриминантных признаков были выбраны следующие семь факторов, имевшихся в информационной базе исследования: количество закрытых договоров (х1), количество договоров в просрочке (х2), сумма полной задолженности по договорам (х3), заработная плата клиента (x4), текущая просрочка(х5), баллы бюро кредитных историй (БКИ) (х6) и возраст (х7).

Дискриминантный анализ проводился средствами универсального статистического пакета IBM SPSS Statistics 20 [2].

В ходе пошагового дискриминантного анализа были исключены два признака:

сумма полной задолженности по договорам и заработная плата.

Основные показатели построенной канонической дискриминантной функцииприведены в таблице 1. 
Таблица 1.

Основные статистики канонической дискриминантной функции

\begin{tabular}{|c|c|c|c|c|c|c|c|}
\hline Функция & $\begin{array}{c}\text { Собственное } \\
\text { значение }\end{array}$ & $\begin{array}{c}\% \\
\text { объясненной } \\
\text { дисперсии }\end{array}$ & $\begin{array}{c}\text { Кумулятивный } \\
\%\end{array}$ & $\begin{array}{c}\text { Каноническая } \\
\text { корреляция }\end{array}$ & $\begin{array}{c}\text { Лямбда } \\
\text { Уилкса }\end{array}$ & $\begin{array}{c}\text { Хи- } \\
\text { квадрат }\end{array}$ & $\begin{array}{c}\text { Уровень } \\
\text { значимости }\end{array}$ \\
\hline 1 & 0,926 & 100,0 & 100,0 & 0,537 & 0,712 & 97,8 & 0,000 \\
\hline
\end{tabular}

Анализ статистических показателей полученной канонической дискриминантной функции позволяет сделать вывод о том, что выбранные дискриминантные признаки обеспечивают высокую степень различения исследуемых классов заемщиков, а построенная дискриминантная функция является состоятельной и обладает хорошей разделяющей способностью.

Анализ стандартизированных коэффициентов канонической функции показал, что наибольший вклад в различение классов заемщиков вносят баллы БКИ $(0,842)$ и текущая задолженность $(-0,347)$. Также существенный вклад в различение классов вносит количество договоров в просрочке

$(-0,229)$. Наименьший вклад в разделение по классам вносят такие признаки как возраст $(-0,038)$ и количество закрытых договоров $(-0,019)$.[3]

На втором этапе дискриминантного анализа проводилась классификация участвующих в исследовании клиентов по двум рассматриваемым классам. На рисунке показано распределение клиентов по числовой оси построенной канонической дискриминантной функции.

Таблица 2.

Результаты классификации

\begin{tabular}{|c|c|c|c|c|}
\hline \multirow{2}{*}{ Класс (исходный) } & \multicolumn{1}{|c|}{ Предсказанная принадлежность к группе } & \multirow{2}{*}{ Итого } \\
\cline { 2 - 4 } & & 0 & 1 & 190 \\
\hline \multirow{3}{*}{$\%$} & 0 & 138 & 52 & 110 \\
\cline { 2 - 4 } & 1 & 21 & 89 & 50 \\
\cline { 2 - 4 } & Не сгруппированные & 18 & 32 & 100,0 \\
\cline { 2 - 4 } & 0 & 72,6 & 27,4 & 100,0 \\
\cline { 2 - 4 } & 1 & 19,1 & 80,9 & 100,0 \\
\hline
\end{tabular}

Основные результаты классификации приведены в таблице 2. В результате анализа 77,5\% исходных сгруппированных наблюдений были классифицированы верно.

Таким образом, построенная на основе дискриминантного анализа скоринговая модель, дает удовлетворительный результат и может быть использована для оценки кредитоспособности клиента при принятии решения о выдаче и параметрах кредита. В условиях жесткой конкуренции кредитных организаций, с одной стороны, закредитованности и низкой кредитоспособности населения, с другой, предложенная модель может стать эффективным инструментом снижения кредитных рисков, способствующего росту конкурентоспособности на рынке кредитования.

\section{Библиографический список}

1. Самойлова С.С. Скоринговые модели оценки кредитного риска / С.С. Самойлова, М.А. Курочка // Социально-экономические явления и процессы. - 2014. - № 3. - С. 92-102.

2. Наследов А. Д. IBM SPSS 20 Statistics и AMOS: профессиональный статистический анализ данных. - СПб.: Питер, 2013. - 399 с.

3. НОЗИМОВ Э. А. ИННОВАЦИОННАЯ ОСНОВА МЕХАНИЗМА РЕГУЛИРОВАНИЯ ИННОВАЦИОННОГО ОБЕСПЕЧЕНИЯ МАЛЫХ ПРЕДПРИЯТИЙ //Экономика и бизнес: теория и практика. - 2020. - №. 3-1. 